http://dx.doi.org/10.35381/s.v.v5i1.1616

\title{
Bioseguridad en el contexto postpandemia
}

Según la Organización Mundial de la Salud (2005), la bioseguridad es un conjunto de reglas y medidas destinadas a proteger la salud humana, encargada también de resguardarse contra los riesgos biológicos, químicos y físicos a los que se está expuesto durante el desempeño de sus funciones ya sean como profesionales o como individuos que forman parte de una sociedad. Como es bien sabido por medio del mecanismo de transmisión del SARS-CoV-2 surge el nuevo reto a la salud pública mundial entre los que se mencionan protocolos y normas de seguridad dentro y fuera de los recintos hospitalarios para el personal que atiende este tipo de casos y para el resto de los miembros que conforman la familia.

Sobre lo anterior la bioseguridad frente al escenario postpandémico implica la higiene de manos con las respectivas técnicas, uso de equipos de protección entre ellos mascarillas, guantes lentes, gorros esterilizaciones, distanciamiento social, uso del antibacterial, desinfección del ambiente entre otros. Mas sin embargo todos estos protocolos representan un reto que lamentablemente no todos lo pueden ni quieren cumplir por una u otras causas entre ellos la falta de recursos, imprudencia, negación, desconocimiento y otros.

En ese sentido, lamentablemente, la humanidad se ha tenido que enfrentar a una serie de consecuencias que en su mayoría no son tan halagadoras de hecho las cifras diarias de los organismos encargados así lo indican, personas fallecidas, otras con complicaciones de alto riesgo, otras quizás lo han superado pero la enfermedad ha dejado secuelas bastante pronunciadas en fin; de allí entonces como podemos observar, las medidas de bioseguridad hasta los momentos siguen siendo uno de los paliativos más oportunos para seguir enfrentando este flagelo mundial. 
Por tanto, nosotros como seres pensantes, no podemos desligarnos de este llamado que hacen los organismos de seguridad a nivel mundial sobre el mantenimiento de los protocolos correspondientes, debemos unirnos todos para que esas cifras bajen y podamos seguir disfrutando de esa calidad de vida que tanto deseamos, en un ambiente donde podamos retomar aquellos saludos y abrazos que tanto necesitamos para hacernos sentir como la verdadera familia que somos ante Dios y ante el mundo.

\section{Dra. Lenys Piña Ferrer}

lenyspina@iieakoinonia.org

Instituto de Investigación y Estudios Avanzados Koinonía, Santa Ana de Coro Venezuela

https://orcid.org/0000-0002-9493-7499 